\title{
KONFIGURASI PEMIKIRAN AL-QABISI TENTANG PENDIDIKAN ISLAM
}

\author{
Muslim \\ Universitas Islam Negeri Sultan Syarif Kasim Riau, Indonesia \\ Email:muslim@uin-suska.ac.id
}

\begin{abstract}
As a jurist, Hafiz al-Qur'an and hadith as well as a good understanding Arabic, al-Qabisi offer educational concepts based al-Qur'an and Sunnah, which impressed normative paradigm of thinking. However, the environmental conditions when it still has relevance to the concept offers, so that form the guidelines for teaching children during the fourth century hijrah. In principle, the development of the Islamic education concept does not just stop in textual normative, need depth assessment of various aspects, sociological, geographical, or philosophy of a nation itself. Very unlikely set curriculum or teaching methods and educational purposes based on one aspect only. Advanced education in the perspective of al-Qabisi can be seen from the realization of the religious environment in the various regions of Islam at the time. Is a natural thing when he established the concept of education that guided in his time.
\end{abstract}

Keywords: Islamic education, religious mileu.

\section{A. Pendahuluan}

Pembicaraan tentang masalah pendidikan adalah suatu hal yang tidak pernah jauh dari pandangan dan pemikiran para pakar pendidikan, di mana pembahasan tentang problematika ini selalu menjadi bahan kajian dan bahasan dalam setiap masa, karena memang pendidikan itu tidak statis melainkan senantiasa berubah dari suatu zaman ke zaman berikutnya. Masalah-masalah pendidikan memang sangat kompleks, karena tidak dapat dinafikan bahwa pendidikan harus berinteraksi dengan manusia dan lingkungannya. Banyaknya problematika pendidkian yang dihadapi manusia dalam kehidupannya sejauh itu pulalah masalah-masalah yang harus dijawab dunia pendidikan dewasa ini.

Sejalan dengan itu, para praktisi dan pemikir pendidikan juga berusaha mengkomunikasikan pemikiran mereka dengan situasi zaman sekarang, sekaligus 
merekonstruksinya sehingga menjadi sebuah konsep yang mempunyai relevansi untuk diaplikasikan pada saat ini. Salah satu pemikir pendidikan itu adalah al-Qabisi yang terkenal dengan ide-ide briliannya tentang berbagai konsep pendidikan Islam. Al-Qabisi adalah salah satu tokoh pendidikan yang terkenal pada abad ke-IV Hijriyah, konsep pemikirannya menjadi rujukan dalam pengajaran anak-anak pada masanya. Dalam makalah ini penulis akan mencoba mengungkap pemikiran al-Qabisi tersebut.

\section{B. Riwayat Hidup al-Qabisi}

Al-Qabisi memiliki nama lengkap "Abu al-Hasan bin Muhammad bin Khalaf," yang lebih dikenal dengan sebutan al-Qabisi, seorang ahli fiqih dari golongan Qairawan. ${ }^{1}$ Ia dilahirkan pada tahun 935 M. dan meninggal dunia pada tahun $1012 \mathrm{M}$. Ibn Khalikan berpendapat, al-Qabisi dilahirkan pada hari Senin setelah hari hari yang kedua bulan Rajab tahun 324 H. Sedangkan al-Sayuthi, Ibn al-'Imad al-Hanbali ibn Fadhlullah al-'Umari, dan 'Abd al-Rahman tidak menyebutkan tentang hari kelahirannya, akan tetapi mereka sepakat bahwa al-Qabisi dilahirkan pada tahun $324 \mathrm{H}$. bertepatan dengan $935 \mathrm{M}^{2}$

Menurut catatan sejarah, bahwa pada masa khalifah Umar bin Khaththab tentara Islam telah sampai ke Afrika Utara bagian Tarablis yang dipimpin oleh Amru bin 'Ash, kemudian dilanjutkan pada masa khalifah Utsman bin 'Affan yang dipimpin oleh Abdullah bin Said bin Abi Sarah. Pada masa inilah tentara Islam telah sampai ke Qairawan kota kelahiran al-Qabisi. Penaklukan Afrika Utara berakhir pada masa Khalifah Muawiyah, khalifah mengutus 10.000 tentara kaum muslimin yang dipimpin oleh 'Uqbah bin Nafi'. Ketika Abdul Malik bin Marwan diangkat menjadi Khalifah ia mengutus Zuhair bin Qais untuk memerangi suku Barbar, kemudian Zuhair kembali memasuki Afrika dan Qairawan, kemudian Abdul Malik bin Marwan memerintahkan Hasan bin Ni'man al-Ghasani untuk memperkuat tentara kaum muslimin dan menetap tinggal di sana bersama kaum muslimin lainnya untuk berkhidmat bagi negeri tersebut dan menyiarkan agama Islam. Maka kaum muslimin yang pertama membawa Islam dan

\footnotetext{
1 Abu al-Falah 'Abd al-Hayy ibn al-'Imad al-Hanbali, Syadzarat al-Dzahab fi Akhbar Man Dzahab, Jilid 3, (t.t. : Dar al-Fikr, t.th.), hlm. 169

2 Ahmad Fu`ad al-Ahwani, Al-Tarbiyah al-Islamiyah aw al-Ta'lim fi Ra`y al-Qabisi, (Cairo : Dar Ihya` al-Kutub al-`Arabiyah, 1955), hlm. 21-25
} 
berkhidmat di Afrika Utara ialah mereka yang terdiri dari para sahabat Nabi dan para tabi'in besar, seperti Abdullah bin Abi Sarah, Ma'bad bin 'Abbas bin Abdul Muthalib, Marwan bin Hakim bin Abi 'Ash bin Umaiyah, Haris bin Hakim, Abdullah bin Zubair bin Awam, Abdullah bin Umar ibn Khaththab dan Abdurrahman bin Abi Bakr.

Penyebarluasan Islam yang dilakukan oleh kaum muslimin ke negara-negara yang belum Islam, baik sejak dari Nabi Muhammad SAW. dan para khalifah sesudahnya, senantiasa memberikan ketenangan dan menjadi rahmat bagi suatu wilayah yang dikuasainya. Oleh sebab itu, selama Islam masih berkuasa di suatu negara atau wilayah, negara tersebut akan senantiasa kondusif dalam tataran masyarakat yang Islami, sehingga mewarnai seluruh aktivitas masyarakat, dan tidak dapat dinafikan bahwa lingkungan yang agamis ketika itu memberikan kontribusi yang positif bagi dunia pendidikan khususnya pendidikan Islam, sekaligus akan mewarnai pendidikan secara keseluruhan. Oleh sebab itu, nilai-nilai pendidikan senantiasa bernuansakan Islami, tidak heran jika al-Qabisi, sebagaimana anak-anak yang lainnya, mempelajari ilmu-ilmu agama terlebih dahulu dan penanaman akhlak-akhlak yang mulia sejak dini, seperti mempelajari shalat, menghafal al-Qur'an dan lain sebagainya.

Namun, tidak berhenti di situ saja, sudah menjadi tradisi di zaman ini, bahwa para penuntut ilmu senantiasa melakukan perjalanan atau rihlah ke luar daerah baik ke negeri Timur, seperti Makkah dan Madinah maupun ke negeri Barat seperti Andalusia atau Spanyol untuk menemui ulama-ulama yang ahli di bidangnya dan mereka mempelajari ilmunya sesuai dengan keahlian yang mereka inginkan secara berhadapan langsung. ${ }^{3}$ Al-Qabisi sendiri, menurut catatan sejarah, melakukan hijrah ke negeri Timur, yakni Makkah dan Madinah, di samping menuntut ilmu, beliau juga menunaikan ibadah haji. Dalam perjalanannya ke Timur al-Qabisi juga singgah dan menetap beberapa waktu di Iskandariyah dan Mesir untuk menuntut ilmu.

Di Mekah, beliau mempelajari ilmu fiqh dan hadis Bukhari melalui ulama terkenal Ali Abu al-Hasan bin Ziyad al-Iskandari salah seorang ulama yang termashur dalam meriwayatkan Imam Malik. Hal inilah yang membuat ia menjadi seorang ahli fiqh Imam Malik. Demikian halnya selama beliau di Iskandariyah beliau juga belajar hadis dengan Abu al-Hasan Ali bin Ja'far. Perjalanannya ke negeri Timur ini

\footnotetext{
${ }^{3}$ Husain Abdul 'Ali, Al-Tarbiyah al-Islamiyah fi Qarni al-Rabi' al-Hijri, (Beirut : Dar al-Fikri al-Arabi, t.th.), hlm. 156
} 
memberikan kefakihan dan menambahnya wawasan beliau dalam ilmu-ilmu keislaman, sehingga ia dapat memberikan corak pendidikan Islam walaupun dalam bentuk sederhana. Salah satu kegemilangan yang beliau peroleh dari perjalanannya ke Timur ialah al-Qabisi adalah orang yang pertama kali membawa kitab Shahih Bukhari ke Afrika Utara. ${ }^{4}$

Oleh sebab itu, para ulama banyak memberikan interpretasi tentang keilmuan yang dimiliki al-Qabisi dan begitu juga tentang sifat-sifat atau keutamaan beliau, alSuyuti misalnya, mengatakan bahwa al-Qabisi adalah seorang huffazh, dan al-Qabisi juga orang yang banyak hafal hadis, ahli teologi, dan ahli fiqh, bersifat zahid dan wara'. Sedangkan Ibn Khaldun berkomentar bahwa al-Qabisi adalah seorang yang ahli hadis, baik dari segi maknanya maupun dari segi sanad hadis. Demikian halnya Qadhi Iyad berpendapat selain al-Qabisi juga seorang yang wara', beliau juga seorang da'i yang mashur dan ahli fiqih di Qairawan. ${ }^{5}$

\section{Karya-karya al-Qabisi}

al-Qabisi adalah seorang ilmuan sekaligus sebagai pemikiran pendidikan yang sangat jenius, di mana banyak karya-karya yang ditinggalkannya dalam berbagai disiplin ilmu pengetahuan sebagai khazanah bagi intelektual muslim, sebagaimana menurut Qadhi Iyad, Ibn Farhun dan Abdurrahman. Kitab-kitab yang dikarang al-Qabisi ialah : 6

1. Al-Muhid al-Fiqh wa Ahkam ad-Diyanah

2. Al-Mub'id min Syibhi at-Ta'wil

3. Al-Munabbih li al-Fithan an Ghawail Fitan

4. Al-Risalah al-Mufashshalah li Ahwal al-Muta'allimin wa Ahkam al-Mu'allimin wa al-Muta'allimin

5. Al-I'tiqadat

6. Manasik al-Hajj

7. Mulakhkhas li al-Muwattha'

\footnotetext{
${ }^{4}$ Gamal Abdul Nasir, Prinsip-prinsip Pendidikan Islam Menurut Ibn Sahnun, al-Qabisi dan Ibn Khaldun, (Kuala Lumpur: Cergas, 2003), hlm. 73

${ }^{5}$ Ahmad Fu'ad al-Ahwani, op.cit., hlm. 28

${ }^{6}$ Mushthafa 'Abdullah al-Qasthanthani al-Rumi al-Hanafi, Kasyf al-Zhunun 'an Asami al-Kutub wa al-Funun, Jilid 5, (Beirut : Dar al-Fikr, 1994), hlm. 549
} 
8. Al-Risalah an-Nasyiriyah fi al-Radd ala' al-Bikriyyah

9. Al-Zikr wa al-Du'a:

Dengan adanya beberapa karya al-Qabisi di atas, menginformasikan bahwa beliau memiliki berbagai disiplin ilmu yang berbeda-beda seperti ilmu fiqh, teologi dan pendidikan. Meski al-Qabisi tidak pernah langsung belajar mengenai ilmu-ilmu pendidikan secara formal seperti pada masa ini. Namun berkat pengalaman beliau menuntut ilmu ke berbagai daerah dan keterlibatannya dalam dunia pendidikan sebagai seorang guru menimbulkan inspirasi pemikirannya terhadap dunia pendidikan. Hal ini terlihat dalam karangann beliau berjudul al-Risalah al-Mufashshalah li Ahwal alMuta'allimin wa Ahkam al-Mu'allimin wa al-Muta'allimin, buku ini menguraikan tentang hal ihwal para pelajar dan hukum-hukum untuk para guru dan pelajar.

Banyaknya karya yang dilahirkan oleh al-Qabisi, telah banyak tersebar di seluruh pelosok dunia termasuk di Indonesia, di mana pemikiran beliau telah banyak diadopsi dan diinterpretasikan kembali sesuai dengan kebutuhan yang ada.

Bahkan jika dipahami lebih dalam, ternyata gagasan al-Qabisi juga mempunyai titik persamaan yang melegitimasi adanya gagasan Islamisasi Ilmu Pengetahuan yang diajukan berbagai sarjana Muslim. Misalnya jika kita melahat pada dua nama yang cukup berpengaruh di dunia Islam dan dipandang sebagai pelopor gerakan Islamisasi Ilmu Pengetahuan: Syed Muhamamd Naquib al-Attas dan Ismail Raji al-Faruqi. Bagi Alatas misalnya, Islamisasi Ilmu Pengetahuan mengacu kepada upaya mengeliminir unsur-unsur serta konsep-konsep pokok yang membentuk kebudayaan dan peradaban Barat, khususnya dalam ilmu-ilmu kemanusiaan. Tercakup dalam unsur-unsur dan konsep ini adalah cara pandang terhadap realitas yang dualistik, doktrin humanisme, serta tekanan kepada drama dan tragedi dalam kehidupan rohani sekaligus penguasaan terhadapnya. Setelah proses ini dilampau, langkah berikutnya adalah menanamkan unsur-unsur dan konsep pokok keislaman. Sehingga dengan demikian akan terbentuk ilmu pengetahuan yang benar; ilmu pengetahuan yang selaras dengan fitrah. Dalam bahasa lain, Islamisasi Ilmu Pengetahuan ala Alatas dapat ditangkap sebagai upaya 
pembebasan ilmu pengetahuan dari pemahaman berasaskan ideologi, makna serta ungkapan sekuler. ${ }^{7}$

\section{Pemikiran Pendidikan al-Qabisi}

\section{Landasan Pendidikan Islam}

Konstruksi pemikiran al-Qabisi tentang pendidikan tentunya tidak terlepas dari back round keahlian yang paling menonjol pada dirinya, yaitu seorang fuqaha Maliki. Secara garis besar, bentuk pemikiran para praktisi pendidikan Islam dapat digolongkan kepada tiga macam. Pertama, mereka yang berpendapat bahwa pendidikan Islam itu harus dalam bentuk yang sama, baik dari segi kurikulumnya, metode, dan tujuannya. Pendapat ini, tidak dapat diterima secara keseluruhan, karena setiap wilayah negara Islam memiliki perbedaan baik secara sosiologis maupun secara geografis. Pendapat yang kedua, bahwa pendidikan diserahkan kepada si pengelolanya atau si pendidik, merekalah yang menentukan kurikulum dan metodenya sesuai dengan tujuan yang mereka inginkan. Pendapat yang ketiga, pendidikan tersebut, tergantung kepada falsafah suatu bangsa yang senantiasa mewarnai kehidupan masyarakat. ${ }^{8}$

Al-Qabisi sebagai seorang ahli fiqh, tidak terlepas dari mazhab Ahli Sunnah (yang senantiasa merujuk kepada al-Qur'an dan hadis), lazimnya para fuqaha senantiasa mengedepankan al-Sunnah terlebih dahulu. Dengan demikian dapat dikatakan bahwa konstruksi konsep pemikiran al-Qabisi terhadap pendidikan senantiasa berorientasikan kepada al-Qur'an dan hadis atau cenderung bersifat normatif. Salah satu contoh, alQabisi berpendapat bahwa seyogyanya bagi seorang guru mengajarkan shalat terhadap anak didik ketika berusia 7 tahun dan memukulnya jika anak tersebut enggan melaksanakan shalat ketika berusia 10 tahun. ${ }^{9}$ Pendapatnya ini berdasarkan hadis Nabi yang berbunyi:

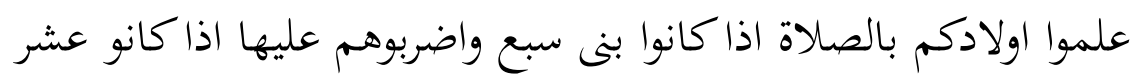

\footnotetext{
${ }^{7}$ Konsep dasar Islamisasi Ilmu Pengetahuan ala Alatas ini bisa dibaca misalnya dalam bukunya Islam \& Secularism. Lihat : Syed Farid Alatas, "Agama dan Ilmu-ilmu Sosial, dalam Jurnal Ilmu dan Kebudayaan Ulumul Qur`an, No. 2, Vol. 5, Tahun 1994

${ }^{8}$ Ibid.

${ }^{9}$ Ibid., hlm. 41
} 
Sehingga orientasi pendidikan menurut al-Qabisi yang pertama dilakukan seorang pendidik atau suatu masyarakat mengajarkan pelajaran-pelajaran agama terlebih dahulu, seperti mempelajari shalat, atau fiqh dalam pengertian yang lebih luas menghafal alQur'an, dan menanamkan al-akhlaq al-karimah. ${ }^{10}$ Oleh sebab itu, al-Qabisi menyarankan seyogyanya membuat lingkungan yang baik dan membiasakan anak dalam lingkungan tersebut dari sejak kecil. ${ }^{11}$ Sebab kebiasaan-kebiasaan yang dihadapi anak di waktu kecil akan membentuk pola kepribadiannya ketika anak sudah dewasa.

Dalam hal ini, kelihatan dengan jelas bahwa kecenderungan konsep pendidikan yang ditawarkan al-Qabisi untuk membentuk kepribadian anak yang memiliki alakhlaq al-karimah. Dengan demikian, kata "التربية" menurut al-Qabisi bermakna "الـثٔهيب dan pada umumnya para pemikir pendidikan yang berdasarkan nilai-nilai normatif (agama) cenderung mendefenisikan pendidikan dengan makna sebagai usaha yang dilakukan masyarakat terhadap perkembangan anak untuk membentuk akhlak yang mulia, misalnya, bagaimana tata cara atau etika seorang siswa duduk di hadapan guru, atau seorang anak tidak boleh mencampuri pembicaraan orang dewasa, dan lain sebagainya. $^{12}$

Harus diakui pula bahwa konsep yang ditawarkan al-Qabisi tidak seluruhnya dapat diterapkan di seluruh negara Islam, apalagi jika dihubungkan dengan pendidikan masa modern sekarang. Di sinilah perlunya kajian-kajian pendidikan yang lebih mendalam lagi. Seperti yang dilakukan para filosof pendidikan. Namun, bukan berarti konsep-konsep pendidikan menurut al-Qabisi tidak mempunyai nilai mendalam lagi. Seperti yang dilakukan para filosof pendidikan, namun bukan berarti konsep-konsep pendidikan menurut al-Qabisi tidak mempunyai nilai dalam pengembangan dunia pendidikan. Bahkan, kontribusi pemikirannya terhadap dunia pendidikan telah memberikan andil yang sangat besar bagi dunia pendidikan itu sendiri terutama pada abad keempat hijrah.

\section{Kurikulum Pendidikan}

Kurikulum pendidikan yang ditawarkan al-Qabisi terhadap anak didik dapat dilihat dalam bentuk yang sederhana. Menurutnya, pendidikan yang pertama kali

\footnotetext{
${ }^{10}$ Husain Abdul Ali, op.cit., hlm. 41

${ }^{11}$ Ibid., hlm. 181

${ }^{12}$ Muhammad Jawad Ridha, Al-Fikra al-Islami, "Muqaddimah fi Ushulihi al-Ijtima'iyah wa alQalamiyah", (t.t. : Dar al-Fikr al-Arabi, tt), hlm. 96
} 
diterima anak adalah dari lingkungan keluarganya, oleh sebab itu al-Qabisi tidak memberikan batasan waktu kapan anak diserahkan ke kuttab (sekolah), karena menurutnya, kuttab adalah perpanjangan tangan dari orang tua siswa untuk mendidik anaknya, apabila orang tua tersebut tidak dapat untuk mendidik anaknya. Meski demikian, menurut al-Qabisi, anak dapat diserahkan ke kuttab ketika anak tersebut telah fasih berbicara atau telah berusia 7 tahun. Pelajaran yang pertama diterima anak di sekolah adalah menghafal al-Qur'an, baik secara individu maupun kelompok, lalu anak mempelajari cara penulisannya.

Secara garis besar kurikulum menurut al-Qabisi dibagi kepada dua macam yaitu: kurikulum pokok dan kurikulum pilihan (penunjang). Pembagian kurikulum ini juga dilatarbelakangi oleh pemahaman bahwa ilmu itu juga terbagi kepada dua macam, yaitu ilmu ll sebagaimana halnya juga al-Ghazali membagi ilmu kepada fardhu a'in dan fardhu kifayah. ${ }^{13}$ Ilmu- ilmu الضرورية ini merupakan kurikulum pokok yang harus diajarkan terlebih dahulu kepada anak didik yang terdiri atas: membaca atau menghafal al-Qur'an, mempelajari shalat, do'a, sebahagian kaedah nahwu kemudian membaca dan menulis. ${ }^{14}$ Sedangkan kurikulum pilihan ialah: mempelajari ilmu hitung, seluruh kaedah nahwu, syair-syair, dan nama-nama hari Arab.

Kurikulum yang ditawarkan al-Qabisi tersebut memang dalam bentuk yang sederhana, sehingga sebahagian kalangan berpendapat bahwa kurikulum yang diterapkan al-Qabisi dalam pengertian yang sempit. Salah satu kelemahan kurikulum tersebut tidak memperhatikan kecenderungan atau minat anak didik. Ahmad Fuwadi alAhwani, misalnya mengkritik kelemahan kurikulum yang ditetapkan al-Qabisi karena tidak memberikan waktu belajar hanya untuk membaca al-Qur`an dan menghafalnya, kemudian menulisnya dan mempelajari ilmu nahu atau tata bahasa Arab. ${ }^{15}$

Terlepas dari kritikan di atas, adalah suatu hal yang wajar, jika bentuk kurikulum yang ditetapkan al-Qabisi lebih cenderung untuk mempelajari ilmu-ilmu agama, seperti shalat, menghafal al-Qur`an jika kita melihat kondisi objektif lingkungan masyarakat ketika itu yang bernuansa agamis. Sehingga kecenderungan orang ketika itu ialah untuk menguasai ilmu-ilmu keislaman, yang bersumberkan al-Qur`an dan al-

\footnotetext{
${ }^{13}$ Husain Abdul Ali, op.cit., hlm. 182

14 Ali al-Jamiyulaty dan Abu al-Futuh al-Tawanisi, Darasah al-Muqaranah fi al-Tarbiyah alIslamiyah, (Cairo: Maktab al-Anjal al-Mishriyah, tt), hlm. 66

${ }^{15}$ Ibid., hlm. 73
} 
hadits. Oleh sebab itu menghafal al-Qur’an adalah suatu keistimewaan ketika itu dan sebagai persyaratan untuk menggali ilmu-ilmu lain.

Uraian tentang kurikulum menurut pandangan al-Qabisi di atas adalah untuk jenjang pendidikan dasar, yakni pendidikan di al-Kuttab, sesuai dengan jenjang yang telah di kenal di masa itu. Al-Kuttab merupakan lembaga pendidikan Islam terlama. AlKuttab ini didirikan oleh orang Arab pada masa Abu Bakar dan Umar, yaitu sesudah mereka melakukan penaklukan-penaklukan dan sesudah mereka mempunyai hubungan dengan bangsa-bangsa yang telah maju.

Al-Kuttab ini memegang peranan penting dalam kehidupan Islam karena mengajarkan Al-Qurean bagi anak-anak diangggap satu hal yang amat perlu, sehingga kebanyakan para Ulama berpendapat mengajarkan Al-Qurean bagi anak-anak dipandang sebagai fardhu kifayah, di samping itu Nabi sendiri menyatakan bahwa belajar itu sangat perlu, sehingga beliau mewajibkan tiap- tiap tawanan perang Badar untuk mengajarkan dua belas orang anak orang- orang Islam sebagai tebusan perang.

Al-Kuttab telah tersebar luas dengan tersebar luasnya agama Islam diseluruh pelosok negeri, dan pembentukan al-Kuttab untuk mengajarkan Al- Qur'an, membaca, menulis dan agama, dianggap sebagai pekerjaaan yang paling mulia dan terhormat di sisi Tuhan, sehingga kebanyakan berlomba-lomba untuk mendirikannya. Seiring berjalannya waktu, al-Kuttab telah banyak didirikan di setiap desa baik yang berdiri di samping masjid maupun yang tidak berdekatan dengan masjid, dari pernyataan tersebut dapat dipahami bahwa al-Kuttab bukanlah lembaga pendidikan yang didirikan oleh perorangan saja.

Pendidikan pada al-Kuttab diperuntukkan untuk semua orang, di dalamnya terdapat anak-anak orang kaya dan anak-anak orang miskin yang sama-sama mendapat pelajaran. Para guru dilarang membeda-bedakan di antara anak-anak orang kaya dan miskin dalam belajar, karena system pendidikan Islam adalah menganut sistem demokrasi, disana tidak ada golongan dalam belajar.

\section{Tenaga Pendidik}

Guru dalam dunia pendidikan adalah salah satu unsur yang amat penting, oleh sebab itu guru seyogyanya memiliki kepribadian yang mulia, sebab sikap dan kepribadian guru, seperti perbuatan dan ucapannya akan memberikan pengaruh terhadap 
perkembangan kepribadian anak. Anak didik senantiasa mempersepsikan guru dalam pikirannya dan selalu mengidolakan gurunya, dan menganggap guru adalah suatu hal yang harus dicontoh. Jika guru yang akan dicontoh anak didik tidak memiliki kepribadian yang mulia, maka perbuatannya akan ditiru anak didik juga.

Menurut al-Qabisi, guru harus menjadi contoh teladan sebagai pendekatan untuk merubah tingkah laku anak didik. Oleh sebab itu guru harus menjauhkan sifat-sifat buruk seperti bersifat kasar, meninggalkan waktu mengajar karena adanya pekerjaan lain, meminta sesuatu terhadap siswa seperti hadiah atau makanan, dan sebagainya. Seyogyanya motivasi yang dijadikan guru untuk mengajar tidak karena ingin mendapatkan pujian atau kehormatan melainkan semata-mata hanya untuk mencari ridha Allah. ${ }^{16}$ Adapun mengenai gaji dalam mengajar menurut al-Qabisi seorang guru tidak salah untuk menerimanya karena sebagai usahanya atau jerih payahnya dalam mengajar.

\section{Hukuman dalam Pendidikan}

Dalam memberikan hukuman, al-Qabisi menyarankan kepada guru untuk tidak memberikan hukuman terlebih dahulu, kecuali setelah memberikan nasehat, pengajaran. Jika hukuman juga harus dilakukan kepada siswa, hendaklah hukuman itu atas dasar unsur mendidik. Tidak bersifat kasar atau balas dendam. Karena hukuman yang dilakukan melalui kekerasan akan menimbulkan kesan yang buruk, baik secara fisik maupun secara psikis. Oleh sebab itu, dalam memberi hukuman memiliki tahapantahapan sebagai berikut:

a. Guru menegur terlebih dahulu, dan berusaha untuk membimbingnya agar anak tidak melakukan kesalahan itu lagi.

b. Jika anak masih melakukannya, guru mencela perbuatan itu, misalnya dengan membedakan dengan teman-temannya, secara otomatis anak tersebut akan mengetahui bahwa perbuatannya itu salah, karena dibandingkan dengan temannya yang lain yang tidak melakukan perbutannya.

c. Apabila dengan cara yang kedua juga tidak memberikan kesan, anak masih juga melakukan kesalahan-kesalahan, maka untuk menjaga agar perbuatan

${ }^{16}$ Ahmad Fu'ad al-Ahwani, op.cit., hlm. 181 
anak yang bersalah ini tidak ditiru teman-temannya yang lain guru boleh melakukan pilihan terakhir yaitu hukuman fisik, dengan catatan tidak sampai merusak fisik anak. ${ }^{17}$

Ketika guru telah akan melaksanakan hukuman, menurut al-Qabisi, hendaklah guru tersebut mempertimbangkan hal-hal sebagai berikut :

a. Dalam melaksanakan hukuman guru tidak dalam keadaan emosional. Sebab bila guru dalam keadaan emosi, dikhawatirkan akan melampaui batas yang akan mengakibatkan kepatalan terhadap anak didik. Al-Qabisi mencontohkan perbuatan Umar bin Abdul Aziz yang menyuruh seseorang untuk memukul seseorang. Namun, ketika Umar bin Abdul Aziz melihat orang yang dia suruh hendak memukul dengan emosi, Umar melarangnya kembali untuk melaksanakan pemukulan.

b. Guru mesti menyadari hukuman yang dia lakukan bertujuan untuk kemaslahatan dan sebagai ancaman bagi anak didik dengan tujuan agar anak didik melakukan perbuatannya itu kembali. Jadi motif hukuman yang dilakukan guru untuk memperbaiki akhlak siswa.

c. Dalam melaksanakan hukuman tidak menimbulkan bekas atau cacat tubuh anak-anak.

d. Hendaklah guru melakukan hukuman dengan sendirinya tanpa melibatkan pelajar atau orang lain, sebab akan menimbulkan perselisihan di antara mereka dan rusaknya persaudaraan.

e. Guru tidak dibenarkan memukul bagian tubuh yang sensitif seperti kepala atau muka.

f. Guru juga dilarang menghukum anak didik dengan cara menghalanginya untuk tidak makan atau istirahat.

Al-Qabisi berpendapat bahwa memberikan hukuman terhadap anak didik dibolehkan dalam Islam, karena Allah sendiri memberikan hukuman dan ganjaran kepada hambanya baik yang masih hidup di dunia maupun kelak di akhirat. Namun makna eksplisit dalam melaksanakan hukuman itu ialah harus diyakini seorang guru

\footnotetext{
${ }^{17}$ Ibid., hlm. 126
} 
sebagai usaha terakhir dalam rangka merubah tindak-tanduk siswa dari yang tidak baik atau kurang terpuji menjadi yang lebih baik.

\section{Pendidikan Akhlak}

Menyangkut dengan pendidikan akhlak, Al-Qabisi meminta para pendidik agar berpegang pada nilai-nilai dan prinsip-prinsip yang didasarkan kepada al-Qur`an dan Sunnah. Ia berkata bahwa siapa yang mengajar anaknya dan memperbagus pengajarannya dan siapa saja yang mendidik anaknya serta memperbagus pendidikannya, orang tersebut telah berbuat baik kepada anaknya dan akan mendapat pahala di sisi Allah. Al-Qabisi menyatakan bahwa antara pendidikan dengan pengajaran saling mengisi. Akhlak mesti dibina oleh keluarga, lembaga pendidikan dan masyarakat umum. Kalau anak menyimpang ataupun melakukan hal-hal yang buruk, itu lebih disebabkan oleh keluarga yang tidak melaksanakan kewajiban mereka. Anak-anak yang telah menyimpang dari perilaku agama perlu diberikan hukuman serta mendidik ke arah yang benar. $^{18}$

Menurut uraian di atas di dalam konsep pendidikan Islam Al-Qabisi, ada beberapa pemikiran atau pandangan Al-Qabisi tentang pendidikan Islam yang meliputi pendidik, peserta didik, tujuan pendidikan, kurikulum, metode pembelajaran, dan lainlain yang berhubungan dengan pendidikan. Al-Qabisi mengemukakan konsep kurikulum yang erat kaitannya dengan ilmu pengetahuan. Ilmu dari Allah harus dituntut oleh setiap manusia, oleh karenanya pendidikan harus membuat seorang anak memiliki kesadaran terhadap hukum Islam melalui pelajaran Al-Qurean dan Hadits.

\section{E. Simpulan}

Kesimpulan yang dapat dipetik dari paparan terdahulu adalah:

1. Berdasarkan bacaan-bacaan yang berhubungan dengan pemikiran al-Qabisi tentang pendidikan Islam dapat disimpulkan bahwa al-Qabisi adalah seorang faqih dan hafizh al-Qur`an dan hadis dan seorang yang memahami bahasa Arab dengan baik. Dengan demikian, konsep-konsep yang beliau tawarkan dalam pendidikan cenderung berlandaskan al-Qur`an dan Sunnah, yang paradigma

${ }^{18}$ Abdullah al-Amin al-Nueemy, Kaedah dan Tekhnik Pengajaran Menurut Ibnu Khaldun dan AlQabisy, (Selangor: Dewan Bahasa dan Pustaka, 1994), hal. 203-205 
pemikirannya terkesan normatif. Meski demikian, kondisi lingkungannya ketika itu masih mempunyai relevansi dengan konsep yang ia tawarkan, sehingga dijadikan pedoman bagi pengajaran anak-anak pada masa abad keempat hijriyah.

2. Pada prinsipnya pengembangan konsep pendidikan Islam tidak hanya berhenti dalam tekstual normatif saja, perlu pengkajian yang mendalam dari berbagai aspek, baik sosiologis, geografis, maupun falsafah suatu bangsa itu sendiri. Sangat tidak mungkin menetapkan kurikulum pendidikan atau metode mengajar dan tujuan pendidikan berdasarkan satu aspek saja.

3. Pendidikan yang maju dalam perspektif al-Qabisi dapat dilihat dari terwujudnya lingkungan keagamaan di berbagai daerah kekuasaan Islam ketika itu. Adalah suatu hal yang wajar jika beliau menetapkan konsep pendidikan yang menjadi pedoman di masanya.

\section{F. Daftar Kepustakaan}

Abdullah al-Amin al-Nuemy, Kaedah dan Tekhnik Pengajaran Menurut Ibnu Khaldun dan Al-Qabisy, Selangor: Dewan Bahasa dan Pustaka, 1994

Abu al-Falah 'Abd al-Hayy ibn al-'Imad al-Hanbali, Syadzarat al-Dzahab fi Akhbar Man Dzahab, Jilid 3, t.t. : Dar al-Fikr, t.th.

Ahmad Fu`ad al-Ahwani, Al-Tarbiyah al-Islamiyah aw al-Ta'lim fi Ra'y al-Qabisi, Cairo : Dar Ihya`al-Kutub al-'Arabiyah, 1955

Ali al-Jamiyulaty dan Abu al-Futuh al-Tawanisi, Darasah al-Muqaranah fi al-Tarbiyah al-Islamiyah, Cairo: Maktab al-Anjal al-Mishriyah, tt

Gamal Abdul Nasir, Prinsip-prinsip Pendidikan Islam Menurut Ibn Sahnun, al-Qabisi dan Ibn Khaldun, Kuala Lumpur: Cergas, 2003

Husain Abdul 'Ali, Al-Tarbiyah al-Islamiyah fi Qarni al-Rabi' al-Hijri, Beirut : Dar alFikri al-Arabi, t.th.

Muhammad Jawad Ridha, Al-Fikra al-Islami, "Muqaddimah fi Ushulihi al-Ijtima'iyah wa al-Qalamiyah", t.t. : Dar al-Fikr al-Arabi, tt

Mushthafa 'Abdullah al-Qasthanthani al-Rumi al-Hanafi, Kasyf al-Zhunun 'an Asami al-Kutub wa al-Funun, Jilid 5, Beirut : Dar al-Fikr, 1994

Syed Farid Alatas, “Agama dan Ilmu-ilmu Sosial, dalam Jurnal Ilmu dan Kebudayaan Ulumul Qur`an, No. 2, Vol. 5, Tahun 1994 
